\title{
Cultural lag: A new challenge for mastitis control on dairy farms in the United States
}

\author{
R. J. Erskine,$^{* 1}$ R. O. Martinez, $†$ and G. A. Contreras* \\ *Department of Large Animal Clinical Sciences, and \\ †Julian Samora Research Institute, Michigan State University, East Lansing 48824
}

\begin{abstract}
Recent changes in the US dairy industry include increases in herd size and the proportion of milk that is produced by large herds. These changes have been accompanied by an increased reliance on hired employees and an increasing role of immigrant labor to perform critical tasks such as milking cows. Thus, there is a growing need for training and education programs for dairy employees because many employees lack previous dairy experience and employee turnover rates are problematic on many farms. Although extension programs have played an important role in the education and support of dairy producers and allied professionals in attaining improved milk quality, dairy employees have limited access to educational programs. Additionally, metrics to assess employee learning are not validated and the ability to sustain work-related behavioral change has not been well described. In this article, we propose a model that may further our understanding of communication and cultural barriers between dairy managers and employees, based on a demonstration project in 12 Michigan dairy herds. As part of this demonstration, a pilot survey was tested to assess the management culture on dairy farms. Results from this survey found that only $23 \%$ of employees across all herds were able to meet with farm management on a regular basis, $36 \%$ of employees did not know somatic cell count goals for the farm for which they worked, and $71 \%$ of employees stated they primarily received training on milking protocols by other employees or that they learned on their own. Latino employees were more likely to not know farm goals or receive primary training on milking protocols from other employees or on their own compared with their English-speaking counterparts. The survey information, along with input from focus group discussions with participating dairy producers, veterinarians, and employees, suggests that extension needs to build capacity for on-farm training
\end{abstract}

Received January 27, 2015.

Accepted July 13, 2015.

${ }^{1}$ Corresponding author: erskine@msu.edu and education for employees to support their engagement within dairy operations.

Key words: extension education, employees, mastitis

\section{INTRODUCTION}

The US dairy industry has become increasingly dynamic as advances in nutrition, genetics, understanding of disease pathogenesis, and technologies associated with feeding, milking, reproduction, and labor efficiency have increased productivity (von Keyserlingk et al., 2013). This development also has driven a marked shift in herd demographics. Average herd size increased from 72 cows in 1996 to 121 cows in 2006, whereas the number of herds decreased from 130,980 to 75,140 during the same period (USDA-NAHMS, 2007). More remarkable has been the rapid intensification of the industry; farms with fewer than 100 cows accounted for $49 \%$ of the country's 9.7 million milk cows in 1992, but just $17 \%$ of the 9.2 million milk cows in 2012. In contrast, farms with at least 1,000 cows accounted for $49 \%$ of all cows in 2012, an increase from just 10\% in 1992 (MacDonald and Newton, 2014). Additionally, 63\% of the milk supply is produced by herds with more than 500 cows (von Keyserlingk et al., 2013). However, the percentage of herds with fewer than 100 cows decreased only marginally, from 83 to $77 \%$ (USDA-NAHMS, 2007).

As the diversity of herd size increases, dairy farms are also becoming increasingly diverse in terms of employment practices and organization (Jackson-Smith and Barham, 2001). Increasing numbers of Latino workers are employed in the dairy industry, which had previously hired relatively few foreign-born laborers (Jenkins et al., 2009). Recent reports have estimated that 41 to $50 \%$ of dairy farms depend on Spanish-speaking foreign labor, $50 \%$ of dairy farms employ immigrant labor, and $62 \%$ of milk comes from farms employing immigrant labor (Baker and Chappelle, 2012; von Keyserlingk et al., 2013). As the role of immigrant labor increases in the US dairy industry, cultural and communication barriers complicate management-employee relationships as Spanish-speaking workers are increasingly seen in jobs 
traditionally held by individuals whose first language is English (Cross, 2006; Stack et al., 2006; Jenkins et al., 2009).

To address this potential cultural and language barrier, education, training, and translation tools have been developed by land-grant universities, consultants, and agricultural agencies to help farms owners manage the changing dairy workforce (Fuhrmann, 2002; Chase et al., 2006, Stack et al., 2006; Jenkins et al., 2009). However, these programs were developed from a management-directed perspective with minimal input from employees, and the effectiveness of employee training, or education programs, relative to farm protocols and productivity has not been evaluated for short- or long-term success. Additionally, many dairy managers are likely to have limited human resource knowledge and management experience and tend not to perceive themselves as employee trainers; this often leads to frustration with protocol drift and a sense that employees are not motivated to engage in the success of the farm beyond prescribed instructions. These and other workplace conditions can contribute to employee turnover, which has been attributed to relationships with management and coworkers and job duties (Billikopf and González, 2012). Taken together, these gaps in the nation's dairy farms constitute a form of cultural lag. That is, there is a gap between the human resource needs arising within the industry's labor force and the capacity of producers and managers to address them.

Although SCC continue to decrease among US dairy herds (USDA-NAHMS, 2013), variability among herds may be partly explained by poor protocol compliance (Fuhrmann, 2002; Brasier et al., 2006). We contend that ineffective training of employees and ensuing protocol drift may prevent some herds from attaining their milk quality goals. This is particularly relevant for mastitis control protocols, as Latino laborers are heavily concentrated in entry-level positions on dairy farms, roles that include milking, maintenance of housing, and administration of therapies such as intramammary infusions of antimicrobial drugs (Valentine, 2005; Stack et al., 2006).

To better define potential barriers to employee training and education and to seek methods to enhance engagement on the part of dairy employees, we describe preliminary findings from an assessment survey to determine the management culture on dairy farms relative to employee training and communication and knowledge of farm goals, and a novel approach for an on-farm education model for employees. These tools were validated on a proof-of-concept basis in a pilot demonstration in 12 herds in Michigan in the winter of 2013-2014.

\section{METHODS}

Approval for use of human subjects was attained by the Institutional Review Board of Michigan State University before the collection of assessment data. During the winter of 2013-2014, we visited 12 dairy herds in Michigan (range of 185 to 3,400 cows; median 670 cows) to perform an evaluation of mastitis control practices (milking procedures, hygiene and environment, herd protocols for infected cow management, and milking equipment) and to test a data collection instrument designed to describe the management culture on each farm, termed the Human Resource Survey (HRS). The instrument consisted of 16 questions concerning milk quality goals for the farm, communication and training opportunities, problem resolution, and the management style of the owners and managers of the farm. Subsequent to the evaluation and HRS, we identified 2 herd-specific opportunities for improvement that would serve as topics for employee education.

We piloted the instrument on each farm through face-to-face interviews with the owners or managers and, afterward, the employees. The objective was not only to obtain their responses to the items on the instrument but also to gain input on how to improve them for subsequent projects (e.g., identify questions in need of clarification or delete other questions that proved to be too difficult to comprehend). Employees on each farm who milked, moved cows to and from the parlor, maintained the housing for cows, or administered mastitis therapy were asked to respond to those questions asked of the managers but from their own perspective. To assure anonymity and inclusiveness and instill confidence to respond genuinely, we conducted the employee interview using a PowerPoint presentation and individual hand-held "clickers" (TurningPoint, Turning Technologies, Youngstown, $\mathrm{OH}$ ). Questions were bilingual (English and Spanish) and were read aloud by a project investigator in the appropriate language; where needed, clarification for each question was offered. Responses to the instrument from each farm were processed and a qualitative comparison was made between overall herd manager responses and those of the employees. For questions that evaluated employee training or knowledge of herd SCC goals, a Fisher's exact test (2-tailed) was used to compare frequency of responses between Spanish-speaking and Englishspeaking employees.

Following the completion of the pilot demonstration, we conducted 5 focus group discussions with participants from the trial. Three of the groups comprised employees; each focus group was conducted solely with employees from the 3 respective farms where they 
Table 1. Responses from employees $(\mathrm{n}=75)$ in 12 Michigan dairy herds to the question "Who usually trains new milkers?"1

\begin{tabular}{lccc}
\hline Item & All employees & English-speaking** & Spanish-speaking** \\
\hline Owners/managers & $22(29)$ & $16(42)$ & $5(14)$ \\
Other workers or self-taught & $53(71)$ & $22(58)$ & $32(86)$ \\
Total & $75(100)$ & $38(100)$ & $37(100)$ \\
\hline
\end{tabular}

${ }^{1}$ Responses were attained anonymously from use of remote response technology. Data are reported as the number (\%) of respondents.

**Frequency of responses between English-speaking and Spanish-speaking employees differed $(P<0.01)$.

worked. One group included 6 herd managers or owners representing 4 farms, and the final group comprised 5 veterinarians from 5 practices. The focus groups allowed participants to critique the demonstration project and provided us a means to obtain more in-depth understanding of perceptions and attitudes regarding the goals and outcomes of our project.

\section{RESULTS AND DISCUSSION}

Among the 12 Michigan dairies, the number of employees interviewed on each farm ranged from 4 to 12 , with a mean of $6.5 \pm 0.2$ (SEM) of employees on each farm. Employees who were interviewed consisted entirely of Spanish-speaking workers on 4 farms, Englishspeaking workers on 3 farms, and a mix of Englishspeaking and Spanish speaking workers on 5 farms. We found slight differences in the number of employees who responded to each question on the HRS (range of 72 to 78 ), which may have reflected differences between employees in the length of their employment on the farm and comprehension of the questions. When herd owners or managers were asked, "Who trains new employees how to milk cows?", 11 of the 12 management teams responded that they perform the training. However, when the employees were asked the same question, only $29 \%$ of 75 employees stated that they learned how to milk from the managers or owners; $71 \%$ said they learned from other employees or they just "learned on the job" (Table 1). The number of employees on a farm who believed they were trained by farm management ranged from 0 to $92 \%$ of the total. Employee responses examined by language (Spanish-speaking and English- speaking) showed that only $14 \%$ of Latino workers said they learned the milking protocols from managers or owners, which was lower than that reported by Englishspeaking workers $(42 \% ; P<0.01)$.

When employees were asked if they knew the SCC goals of the dairy farm for which they worked, $64 \%$ agreed with the goals as stated by farm management and $36 \%$ were unaware of the goals or did not know the correct SCC level (Table 2). The proportion of employees who correctly stated the SCC goals for each farm ranged from 14 to $100 \%$. As with the question regarding training of milking protocols, English-speaking workers $(87 \%)$ were more aware of the herd SCC goals than were Spanish-speaking employees $(41 \%, P<0.001)$.

Seventy-seven percent of employees across all herds participated in team meetings only when there were problems or not at all (Table 3). Within herds, 0 to $71 \%$ of the employees responded that regular team meetings existed.

These data suggest that a misperception exists among herd owners and managers regarding employee training efforts. This may be exacerbated on those farms that lack prescribed communication opportunities among personnel; for example, the high proportion of employees who responded that there was a lack of regular team meetings or that they only met when there was a problem could be perceived as a punitive management style among employees. Retention of Latino employees varies by region and employment of Latino employees is of shorter duration than that of non-Latino employees (Stack et al., 2006; Billikopf and González, 2012). Considering that employee turnover is a problem on many farms (R. J. Erskine, unpublished data), the need for

Table 2. Responses from employees $(\mathrm{n}=75)$ in 12 Michigan dairy herds to the question "Do you know the somatic cell count goals for this dairy farm?"1

\begin{tabular}{|c|c|c|c|}
\hline Item & All employees & English-speaking*** & Spanish-speaking $* * *$ \\
\hline In agreement with response from farm owners or managers & $48(64)$ & $33(87)$ & $15(41)$ \\
\hline Not in agreement with response from farm owners or managers & $27(36)$ & $5(13)$ & $22(59)$ \\
\hline Total & $75(100)$ & $38(100)$ & $37(100)$ \\
\hline
\end{tabular}

${ }^{1}$ Responses were attained anonymously from use of remote response technology. Data are reported as the number (\%) of respondents.

***Frequency of responses between English-speaking and Spanish-speaking employees differed $(P<0.001)$. 
Table 3. Responses from employees $(\mathrm{n}=78)$ in 12 Michigan dairy herds to the question "How often do you meet with managers and employees in other shifts or areas of the farm for regular team meetings?"1

\begin{tabular}{lrc}
\hline & \multicolumn{2}{c}{ All employees } \\
\cline { 2 - 3 } Frequency & No. & $\%$ \\
\hline Monthly & 10 & 12.8 \\
At least 3 times per year & 3 & 3.8 \\
Once or twice per year & 5 & 6.4 \\
Only when there is a problem & 52 & 66.7 \\
Never & 8 & 10.3 \\
Total & 78 & 100 \\
\hline
\end{tabular}

${ }^{1}$ Responses were attained anonymously from use of remote response technology.

effective and consistent communication, training, and education is critical for the prevention and control of mastitis.

Our pilot demonstration suggested that employees lag behind the understanding of management practices on dairy farms regarding mastitis prevention and control, even though they are performing a greater role in the critical work of milking, cleaning barns, observing the health of cows, and so on. From an extension education standpoint, we may have lagged behind the cultural changes brought about by demographic changes in the labor force in the dairy industry. In a separate question from the HRS, 36 of 74 employees (49\%) stated that they receive no education regarding mastitis control and management, and only 12 of $74(16 \%)$ stated they receive education (e.g., videos, consultant or veterinary visits, workshops) on a regular basis. Thus, a new approach for enhancing the education for dairy employees may be needed to augment extension education models. However, we are in an environment of decreasing resources and greater time constraints on extension educators and specialists, even as the demand for more personalized instruction such as workshops, focus groups, and dairy advisory teams is increasing (Chase et al., 2006). Therefore, it is likely that we will need to enlist and facilitate education amplifiers who spend considerable time on dairy farms, develop professional relationships with employees, and apply their expertise in employee training and education.

During the course of our pilot project, we developed learning resources (lessons, learning objectives, and metrics of farm goals) for use by veterinarians on each of the 12 farms. The learning resources varied by farm and depended on the particular observations and deficiencies that were determined during the course of the milk quality evaluation. Additionally, we provided visual aids in the form of a "Quality Milk Corner" that included a poster board for employees to serve as a focal point for learning about herd goals, metrics, and educational materials. In effect, we tested the ability of veterinarians to serve as "on-farm science teachers" for the employees to help promote better understanding of the protocols on the farm, and ultimately to attain more consistent and sustained practice of mastitis control protocols.

During the focus group discussions at the completion of the demonstration project, employees strongly expressed their appreciation for the education program, which helped them better understand why they do their tasks and the importance of those tasks. The education program also instilled a sense of respect, to which one employee added, "Without understanding why we do things, it's like being told as a kid not to touch the hot stove but never being told why you shouldn't do it." Dairy producers also noted the positive attitude of employees brought about by veterinarian-initiated education activities and cited several examples of improved interest and team effort on the part of the employees in the work they performed. Additionally, producers expressed interest in continuing this program and believed it held economic value for their operation. One of the critical comments brought forth by veterinarians was the need for support in educating Latino employees, both for interpretation and comprehension of learning materials and to help navigate cultural differences (e.g., ensuring that employees believe that the veterinarian is there to build a relationship with them and not to report back to the owner and get them in trouble).

We believe that engaged employees take the initiative and work to get the desired result for the dairy operation beyond just "doing the job." Engaged employees understand the goals of the farm, how things must get done to achieve those goals, and why they should follow protocols to attain those goals. We further believe that to close the gap between employee knowledge and dairy farm production, extension personnel should build capacity to support on-farm education and facilitate "science teachers"- be they veterinarians, herd managers, or other professionals who can have a more durable impact on employee engagement and thereby improve productivity on dairy operations in the context of the major changes in the industry.

\section{SUMMARY}

Translational education provided by extension has contributed to the success in many areas of dairy operations (Chase et al., 2006). Models of education have included seminars, short courses, workshops, on-farm support and consultation, websites, articles, and newsletters. Although these methods have targeted herd owners, managers, and support professionals such as veterinarians and nutritionists, it is unknown how well 
this traditional extension platform has engaged employees generally, especially in the emerging context of a changing labor force. Employees who work long hours may not be fully receptive to learning after traveling to attend structured education programs such as a 3 -h workshop. Additionally, literacy and education levels can be problematic for some employees, and the application of what has been learned on farm sites generally relies on the herd owners or managers, many of whom are not trained or inclined to serve in the role of educator. These concerns were supported by the preliminary results from our HRS, which indicated that there are considerable training and communication barriers between herd owners and managers and their employees, especially Spanish-speaking employees.

\section{ACKNOWLEDGMENTS}

This project was supported by Agriculture and Food Research Initiative Competitive Grant no. 2013-6800420439 from the USDA National Institute of Food and Agriculture (Washington, DC).

\section{REFERENCES}

Baker, D., and D. Chappelle. 2012. Health status and needs of Latino dairy farm workers in Vermont. J. Agromedicine 17:277-287.

Billikopf, G., and G. González. 2012. Turnover rates are decreasing in California dairies. Calif. Agric. 66:153-157. http://dx.doi. org $/ 10.3733 /$ ca.v066n04p153.

Brasier, K., J. Hyde, R. E. Stup, and L. A. Holden. 2006. Farm-level human resource management: An opportunity for extension. J. Ext. 44:rb3 http://www.joe.org/joe/2006june/rb3.php.
Chase, L. E., L. O. Ely, and M. F. Hutjens. 2006. Major advances in extension education programs in dairy production. J. Dairy Sci. 89:1147-1154.

Cross, J. 2006. Restructuring America's dairy farms. Geogr. Rev. 96:1-23.

Fuhrmann, T. J. 2002. Quality milk starts with quality management. Pages 131-139 in Natl. Mastitis Counc. Reg. Mtg. Proc., Orlando, FL. Natl. Mastitis Counc. Inc., Verona, WI. http://www nmconline.org/articles/qualmgt.pdf.

Jackson-Smith, D., and B. Barham. 2001. Dynamics of dairy industry restructuring in Wisconsin. Res. Rural Sociol. Dev. 8:115-139.

Jenkins, P. L., S. G. Stack, J. J. May, and G. Earle-Richardson. 2009 Growth of the Spanish-speaking workforce in the Northeast dairy industry. J. Agromedicine 14:58-65.

MacDonald, J., and D. Newton. 2014. Milk production continues shifting to large farms. US Department of Agriculture, Economic Research Service, Amber Waves, Dec 1, 2014. Accessed April 28, 2015. http://www.ers.usda.gov/amber-waves/2014-december/ milk-production-continues-shifting-to-large-scale-farms.aspx\#. VJc6Ff8KQA

Stack, S. G., P. L. Jenkins, G. Earle-Richardson, S. Ackerman, and J. J. May. 2006. Spanish-speaking dairy workers in New York, Pennsylvania, and Vermont. J. Agromedicine 11:37-44.

USDA-NAHMS (National Animal Health Monitoring System). 2007 Dairy 2007 Part II: Changes in the U.S. dairy cattle industry, 1991-2007. Accessed January 14, 2015. http://www.aphis.usda. gov/animal_health/nahms/dairy/downloads/dairy07/Dairy07_ dr_PartII.pdf.

USDA-NAHMS (National Animal Health Monitoring System). 2013 Determining U.S. milk quality using bulk tank somatic cell counts, 2012. Accessed January 14, 2015. http://www.aphis.usda. gov/animal_health/nahms/dairy/downloads/dairy_monitoring/ BTSCC_2012infosheet.pdf.

Valentine, B. E. 2005. Uniting two cultures: Latino immigrants in Wisconsin's dairy industry. University of California, San Diego. Accessed May 2, 2015. http://ccis.ucsd.edu/wp-content/uploads/ WP_121.pdf.

von Keyserlingk, M. A. G., N. P. Martin, E. Kebreab, K. F. Knowlton, R. J. Grant, M. Stephenson, C. J. Sniffen, J. P. Harner, A. D. Wright, and S. I. Smith. 2013. Invited review: Sustainability of the US dairy industry. J. Dairy Sci. 96:5405-5425. 